laboratory animals and of the naturally occurring tumours of frogs, birds and mammals, including cattle now known to be associated with viruses. He a'so describes, in even greater detail, the diseases with which he has himself been most closely associated, the virus-induced murine leukæmias and tumours. Dr. Gross writes simply, clearly and with great enthusiasm and every chapter is of absorbing interest.

The general medical reader will find the simple technical descriptions of the handling of filtrates most helpful in understanding this immensely complex field and will be especially grateful to Dr. Gross for explaining the origins and characteristics of the now famous strains of laboratory mice that figure so largely in modern research. It is a pity that the chapters dealing with the author's own studies are the least satisfactory. This is, no doubt, because Dr. Gross is so deeply involved in this growing point of tumour virology that he is unable to survey the subject with the necessary detachment.

A word of warning is necessary to the non-specialist. Dr. Gross is convinced from his enormous experience that viruses are likely to be the commonest single cause of malignancy in animals, and as a working hypothesis he would suggest that there is no reason to exclude human malignant disease. He explains the action of chemical carcinogens and of ionizing radiations on the basis of the unmasking of latent viruses, and he makes no real attempt to explain how the presence of the virus within the cell could induce malignant change. $\mathrm{He}$ may yet prove to be right, but many would feel that his views are further ahead than the facts so far available allow. Few clinicians would, for example, agree with him that women with a family history of cancer should refrain from breast-feeding their children. Nevertheless, this is an entrancing book. It is well produced and lavishly illustrated, and there are excellent photographs not only of the viruses, but of their discoverers. The key references are given at the end of each chapter and there is a useful author index and an adequate general index.

\section{Problems of Pulmonary Circulation}

Ciba Foundation Study Group No. 8. Edited by A. V. S. DE REUCK, M.SC., D.I.C., A.R.C.S., and M. O'ConNor, B.A. Pp. viii +96 , illustrated. London: J. \& A. Churchill. r96r. 30s.

In the last few years the pulmonary circulation has been intensively investigated from many standpoints. On November 18, 1960, the Ciba Foundation held a study group devoted to the topic in honour of Professor G. Liljestrand. The participants included animal physiologists, clinical physiologists, clinicians, radiologists and pathologists, interested both in the circulatory and pulmonary problems of the lesser circulation. The papers and discussions have been published and edited with the customary skill of the Ciba Foundation and form a very useful and inexpensive source of reference.

\section{Symposium on Anticoagulant Therapy}

Report of the Proceedings. Edited by Professor Sir G. W. Pickering, M.A., D.SC., M.D., F.R.C.P. Pp. xii +284 . London: Harvey and Blythe. I96r. 2 Is.

Anonymous hosts made possible the gathering of 55 distinguished participants. The result is a most interesting and stimulating collection of fact and opinion. Of necessity the number of aspects considered is limited. Notable omissions include heparin and the correction of the deficiencies induced by anticoagulant drugs. Among the discernible trends are the decline in popu- larity of the quick one-stage prothrombin test for conntrolling treatment, the gradual recognition of the patients likely to be most benefited and the slow but sure progess of therapeutic fibrinolysis. We are grateful that the proceedings of the symposium have been made generally available at a most reasonable price.

\section{Pathology of the Nervous System: A Studerit's Introduction

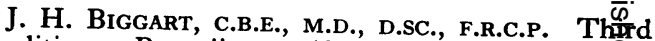
edition. Pp. xii +368 , with 239 illustrations 22 coloured plates. Edinburgh and London E. \& S. Livingstone. 196r. 40s.

The appearance of a third edition of this book $\vec{i}$ a measure of its tried and proven value. It is simple and clear in exposition, beautifully illustrated and admirably produced. The field covered is wide with undue emphasis or imbalance. Though some problegins such as the relationship between vascular occlusions and cerebral infarctions are oversimplified, it is because the book is what it sets out to be, a studeno's introduction, which avoids confusing the beginner whth a welter of evidence and conflicting views. It will wimo doubt continue to enjoy its well-established reputation.

\section{Carcinoma of the Colon}

(1)

Edward G. MuIR, M.s., F.R.c.s. Pp. vii +1 연, illustrated. London: Edward Arnold. 1961. 4र्25.

This monograph, it is stated, has been written essentially for surgical postgraduates and young surgeoms in training. Despite this the book contains nothing that is new and cannot be found in any one of the seweral larger current works on this subject. Neverthelesso t tere book may have a value in that it re-emphasizes again all the well-known difficulties and pitfalls surratiding the management of carcinoma of the colon. 7 various factors resulting in delays in diagnosis are very well discussed and once again the varied symptomatolo of colonic cancer, especially that on the right side, ofs emphasized by an impressive list of patients, many of whom had had a negative barium meal or cholecyst 8 gram during the early part of their illness. Similar examples can be seen almost daily in any general surgical out-patient department and, despite all the well-knowh cliches of surgical teaching, it is an astounding faet that $20 \%$ of all patients attending hospital with cancer of the rectum have never had a rectal examination; this figure also accords with the experience of most surgeoms interested in this subject. The plea for the avoidance of a colostomy where possible, especially as a means palliation, is timely.

The book is reasonably priced, is easy to read and the diagrams are clear and well reproduced.

\section{Problems of Infection, Immunity and Allergy} Acute Radiation Diseases

N. N. Klemparskaya, O. G. Alekseyeva, R. R Petrov and V. F. Sosova. Translated from the Russian. Pp. viii +165 , illustrated. Oxfor $\$$ ? London, New York and Paris: Pergamon Press,
r96r. 50s.

The amount of information made available to Western readers by this recent translation from the Russia encourages one to hope that there will be more to follow If the information does not follow the current pattern of research outlined in our own journals, it is neithen surprising nor disadvantageous, and the quantity of material reviewed is likely to be extremely valuable to workers engaged in radiobiological and immunologica research. 
Parts of the book are more valuable than others, and some original work of the authors on bactericidal properties of skin, very detailed changes reported in bacterial flora, and some observations on local hypersensitivity phenomena are particularly interesting. There are also some instructive experiments on the changes induced in the antigenic structure of tissues following irradiation and some unexpected hypotheses as to the immunological nature of radiation sickness.

This latter antedates most of the work carried out in the Western world on auto-immune diseases, and it is probable that the techniques developed for these studies have since been applied to the hypothesis raised by the authors. The results would be of great interest.

That the book fails to read easily is probably not the fault of the translators, as each paragraph runs smoothly in itself. Rather it is more the result of the review of a vast amount of information which forces the authors into dwelling briefly on a great diversity of material.

The absence of information on the immunological status of established chimeræ and the changes in circulating antibodies reflect both the different direction Soviet research is taking and the original date of publication (1958) - the most recent reference to the British and American literature is r 956 . None the less, the overall picture, if not complete, is extremely impressive and helpful, as it supplies information in many fields where we are largely ignorant. It is to be hoped that there will be more such interchanges of information, which, if reported in similar detail, should be of immense value to workers in these fields.

\section{Progress in Medical Genetics, Vol. I}

Edited by A. G. Steinberg, PH.D. Pp. viii $+34 \mathrm{I}$, illustrated. New York and London: Grune and Stratton. 1961. \$9.75.

Progress in medical genetics has been extremely rapid over the last decade. The reasons for these advances are varied and numerous; the initial impetus, however, probably came from the demonstration of the genetic determination of the blood groups in man and of their variable distribution among the populations of the world.

With the growing interest in human genetics it has become almost impossible to keep abreast of the rapid advances which have been made in the various fields. This volume is aimed at presenting up-to-date reviews of these topics in a manner which is acceptable to the clinician, the geneticist and the student. It is probable that each of these academic groups will find some chapters of interest, for the topics reviewed include both general and more specialized subjects.

The study of mutation is undoubtedly one of the most important fields of human genetic research and also one of the most difficult fields in which to gain useful information. Dr. C. F. Crow presents a generalized survey of this topic, with special emphasis on the problem of detection of mutants and estimation of the mutation rate. Unfortunately, however, very little space is devoted to the factors affecting mutation rate, factors which will be of increasing importance in this atomic era.

Professor J. B. S. Haldane presents a very readable account of the processes of natural selection in man. He discusses the action of selection, including medical practice, in altering gene frequencies in relation to such factors as the breeding system and population fitness. Professor Haldane concludes that "we now know less about natural selection in man than I knew 30 years ago'! Perhaps this is but a reflection of his preference" to live in a country where the assortment of human genes differs from that of Europe and North America to a country with good libraries'!

Knowledge of experimental embryology and developmental genetics is rapidly increasing. As yet most of the advances are too recent to assess their implications with respect to mankind. Professor F. Clarke Frazer presents an up-to-date review of this field with special reference to congenital malformations and of their possible relationship to medical genetics.

A volume of this nature would be incomplete without some chapters devoted to human blood groups; Dr. C. A. Clarke lucidly reviews the subject of blood groups and human disease, whilst Drs. Levene and Rosenfield deal with the subject of ABO incompatibility. Both of these otherwise excellent chapters are, however, marred by several minor faults, such as the failure of the total $\chi^{2}$ in Table 2 of Clarke's chapter to agree with that presented in the text. Moreover, in the chapter by Levene and Rosenfield two tables appear which are not even referred to in the text.

The remaining chapter devoted to the genetics of blood groups is a very lengthy review by Drs. Rucknagel and Neel of the hæmoglobinopathies. All of the many aspects of the human hæmoglobins are considered in somewhat excessive detail. Unfortunately, no summary of the information is given, so that readers with only a cursory interest in this field are obliged to plough through over Ios pages of rather heavy text.

The final two chapters are devoted to subjects which will become of increasing importance as techniques for the analysis of genetic phenomena in man. Professor Newton E. Morton considers the morbidity of children from consanguineous marriages and the genetic information which may be gained from such a study, whilst Dr. Ferguson-Smith discusses chromosomes and human disease. It is this last subject which has perhaps the most popular appeal to both the clinician and geneticist, for it is in this field that some of the most spectacular discoveries in human cyto-genetics have been made in recent years.

Dr. Ferguson-Smith presents a concise review of the literature and relevant background information. But in doing so he states that genetic phenomena which have recently been found in man may now also be found in Drosophila. In truth, they have, in fact, long been known in Drosophila. This final chapter is further marred by the contents of Table 5 being clearly inconsistent with the actual information, even though it is presented correctly in the text.

The book itself is well produced and edited except for a few minor printing errors, a striking one being found in the list of contents, where the eighth chapter is described as: 8. CHOMOSOMES AND HUMAN DISEASE.

It is to be hoped that further volumes in this series will appear at not too infrequent intervals.

\section{The Premature Baby}

V. Mary Crosse, O.B.E., M.D., D.P.H., M.M.S.A., D.o.R.C.o.G. Pp. viii +266 , illustrated. London: J. \& A. Churchill. I960. $24 s$.

The revised and reprinted version of this well-known little book will be, without doubt, popular with students and those concerned with the management of premature babies, as it has been so notably over the last 16 years. The work, now in its fifth edition, has once again been brought up to date and this has entailed the complete rewriting of several parts. The book, nevertheless, remains of modest size which has always been one of its attractions. The author has had an unrivalled experience with these small babies over a period of some 